\title{
Virtue Epistemology and Explanatory Salience
}

\author{
GEORGI GARDINER \\ Rutgers University
}

\section{Virtues and Knowledge}

A skilled birdwatcher and a novice walk in the forest. 'That is a flycatcher' observes the birdwatcher carefully, whilst the other randomly guesses 'That is a flycatcher'. Margaret reviews her understanding of thermodynamics and concludes 'I will pass the upcoming test'. Lauren worries about the test, but wishfully believes she will also pass.

In each pair of cases the first person knows the relevant proposition, whilst the second person doesn't. Plausibly this is because in the first case of each pair, the person forms their belief through appropriate cognitive skills and capacities such as perception and good reasoning. In the second, the person does not use appropriate skills and capacities. Instead the belief is formed through guesswork and wishful thinking. As these cases indicate, epistemic character and capacities play an important role in coming to know. A belief that was formed irresponsibly, rashly, or without requisite epistemic abilities does not qualify as knowledge, even if true.

Virtue epistemology holds we can understand the nature and value of knowledge through the notions of epistemic character and virtues (Baehr 2004; Baehr 2008; Battaly 2008; Turri, Alfano, and Greco 2017). Some virtue epistemologists posit that a true belief's being virtuously formed is a necessary condition on knowledge; a belief does not qualify as knowledge, in other words, unless formed through epistemic virtue. A stronger claim holds that a true belief's being virtuous formed is both necessary and sufficient for knowledge. ${ }^{1}$ A natural first attempt to develop this view holds that a belief is known iff it is both true and virtuously formed.

But this view soon faces problems. Consider a standard Gettier case (Gettier 1963), adapted from Chisholm (1966).

Roddy the Shepherd. Roddy the shepherd observes a sheep-shaped object in normal lighting across a field. As a shepherd with keen eyesight, Roddy is usually able to recognize sheep. Roddy accordingly forms the belief 'there is a sheep in that part of the field'. But what Roddy sees is not a sheep but a sheep-shaped rock. Unbeknownst to Roddy, a sheep grazes behind the rock. This hidden sheep renders Roddy's belief true.

Roddy's belief is both true and virtuously formed, but is not knowledge: the belief was only luckily true and Roddy's epistemic abilities were disconnected from the truth of his belief. This example suggests a belief's being both true and virtuously formed does not suffice for knowledge.

The key response to Gettier cases examines why Roddy lacks knowledge, and applies this diagnosis to amend the account of knowledge. I articulated above two central defects in 
Roddy's belief: his belief is merely luckily true; it could easily have been false. And there is a disconnection between Roddy's epistemic abilities and the fact the belief is true.

Focusing on the first defect, one recent virtue-theoretic approach holds that Gettier cases show that focusing only on the virtues, capacities, and character traits of the person is insufficient for an account of knowledge. A person might apply appropriate abilities and yet her belief might be true merely by luck; focusing on the character and competence of the person will never eliminate merely luckily true beliefs. Instead we must augment virtuetheoretic conditions with a separate condition, such as an explicit anti-luck or anti-Gettier condition, to preclude Gettier-style luck (Pritchard 2012; Riggs 2007; Lord (forthcoming), and Coffman (forthcoming)). The approach maintains virtuous formation is a necessary condition on knowledge, but denies it is sufficient.

Alternatively, one might focus on the second defect: the disconnection between Roddy's belief-forming abilities and the truth of the resultant belief. Although Roddy formed his belief virtuously, his belief is not true because virtuously formed. It is true by chance. This diagnosis of Roddy's belief recommends modifying the virtue-theoretic account to include a relation between the belief being virtuously formed and the belief's being true. The thought continues: knowledge is true belief where one arrives at the truth because one's belief is virtuously formed. (Sosa 1988 and 1991; Greco 2003; Zagzebski 1996; and Riggs 2002). ${ }^{2}$

Ernest Sosa defends this view. Sosa writes: "Knowledge is true belief out of intellectual virtue, belief that turns out right by reason of the virtue and not just by coincidence" (1991: 277). John Greco develops this view. Greco writes:

When we say that $\mathrm{S}$ knows $\mathrm{p}$, we imply that it is not just an accident that $\mathrm{S}$ believes the truth with respect to $\mathrm{p}$. On the contrary, we mean to say that $\mathrm{S}$ gets things right with respect to $\mathrm{p}$ because $\mathrm{S}$ has reasoned in an appropriate way, or perceived things accurately, or remembered things well, etc. We mean to say that getting it right can be put down to S's own abilities, rather than to dumb luck, or blind chance, or something else. (2003: 116)

This response employs a purely virtue-theoretic response to Gettier cases: a Gettiered belief is true and virtuously formed, but it is not true because virtuously formed. Since this response does not appeal to supplementary non virtue-theoretic conditions, such as an explicit anti-luck or anti-Gettier condition, advocates maintain that virtuously-formed true belief is both necessary and sufficient for knowledge.

This account of knowledge holds,

Robust Virtue Epistemology. S knows that p iff S's belief that $p$ is true because it was formed with epistemic virtue.

In short, knowledge is true belief through cognitive virtue. We can call this family of views 'robust virtue epistemology'. 'Robust' reflects the claim that virtuously-formed true belief suffices for knowledge, and no other conditions are invoked to explain the nature and value of knowledge. 
Robust virtue epistemology enjoys several virtues. It posits an elegant, simple structure for knowledge. (Certainly more simple than the rival approach described above, which posits a separate anti-luck condition. $\left.{ }^{3}\right)$ On this view, knowledge is a species of the genus success through ability. This simple structure suggests an explanation of the value of knowledge: plausibly success through ability is distinctively valuable. ${ }^{4}$

\section{A Dilemma for Robust Virtue Epistemology}

The account presented above is schematic. To flesh out the view, detail must be supplied about the nature of epistemic ability or virtue. I return to epistemic ability in section five. Advocates must also interpret 'because' in their formulation; what does it mean, in other words, to say a belief is true through cognitive virtue? I focus on the 'because' relation in sections three and four.

But even as a mere schema, robust virtue epistemology faces a dilemma. ${ }^{5}$ We can illustrate this dilemma with two putative counterexamples, which appear to pull robust virtue epistemology in conflicting directions: attempts to rescue the view from one line of objection render the view more vulnerable to the other. Consider the following vignette.

Simple Testimony Case. Having just arrived at the train station in Chicago, Morris wishes to obtain directions to the Sears Tower. He looks around, approaches the first adult passer-by that he sees, and asks how to get to his desired destination. The passer-by, who happens to be a Chicago resident who knows the city extraordinarily well, provides Morris with impeccable directions to the Sears Tower by telling him that it is located two blocks east of the train station. Morris unhesitatingly forms the corresponding true belief. (Quoted from Lackey 2007: 352.)

This is a mundane instance of testimony; we think Morris knows. Much of what we usually consider knowledge is gained via simple testimony. Denying Morris knows would demote much we had considered knowledge to some lesser epistemic standing, rendering many intuitive knowledge attributions inaccurate.

Critics of robust virtue epistemology contend Morris's knowledge fails to satisfy the posited conditions: the true belief is not due to Morris's abilities, but rather it is due to the testifier's abilities.

One natural response to this challenge construes the conditions of robust virtue epistemology more permissively: in order to satisfy the conditions of robust virtue epistemology, the person's role need not be the most important causal factor. It suffices if the person's abilities are one contributing factor amongst many. This response allows that when a person comes to know they might be significantly aided by other factors, such as informants, books, instruments, calculators, and so on. This amendment handles cases of simple testimony because even if Morris does not play the most important role, he plays some role in his forming a true belief. He satisfies these weaker conditions. Thus plausibly the modified view better reflects the extension of knowledge. 
But this weakening of robust virtue epistemology generates problems: the permissive conditions are too easily satisfied. This is the dilemma's second horn. Consider the following case, adapted from Goldman (1976).

Barn Façade County. Barney drives through a valley and spots what is in fact a barn. He forms the corresponding belief, 'there is a barn in that part of the field'. His eyesight is good, the light is clear, and Barney certainly has the capacity to distinguish barns from, say, houses and tractors. Unbeknownst to Barney a period drama was recently filmed in the valley, which is currently dotted with fake barns. These façades resemble the barn Barney sees, but they are mere two-dimensional façades. Had Barney seen a façade, rather than the sole genuine barn, his corresponding belief would have been false.

Plausibly Barney's true belief is too lucky to qualify as knowledge; he could so easily have been wrong. And Barney cannot distinguish barns from the many nearby facades. But Barney's eyesight was functioning well, and he formed a true belief through seeing a real barn. The case differs from Roddy the shepherd, who believed he saw a sheep but in fact saw a rock. Barney was not mistaken about what he saw. There is a non-deviant causal chain between his eyes and the barn. Unlike standard Gettier cases, where luck intervenes between the belief and the fact, in this case the 'luck' resides in the environment: since the environment is unfriendly, Barney's belief is merely luckily true (Pritchard 2005 and 2010).

Barney's eyesight and barn-recognition faculties play some role in why Barney formed a true belief; they are one contributing factor amongst many. Barney thus satisfies the proposed weakened conditions of robust virtue epistemology. And, yet, he arguably fails to know.

The theorist might respond that although Barney's epistemic abilities play a role in why his belief is true, the most significant factor is luck: by chance Barney spotted the one genuine barn. But using this insight to amend robust virtue epistemology exacerbates the problem illustrated by the simple testimony case. If in cases of knowledge the person's abilities must play a large role - underwriting why Barney lacks knowledge - how can we then acquire knowledge via testimony, where plausibly the largest role is the informant's? The two cases appear to pull robust virtue epistemology in opposing directions.

One central question the dilemma raises, then, is what does it mean to say the belief is true because it was formed with cognitive virtue? This relation cannot be too demanding, because of testimonial knowledge, nor can it be too permissive.

\section{Salience and Virtue Epistemology}

Greco advances one of the most developed accounts of virtue epistemology's 'because' relation. He understands the 'because' relation as an explanatory relation; in cases of knowledge, S's abilities are salient in a causal explanation of why $\mathrm{S}$ believes truly that $\mathrm{p}$. Greco claims:

In cases of knowledge, $\mathrm{S}$ believes the truth because $\mathrm{S}$ believes from intellectual ability S's believing the truth is explained by S's believing from ability. But the success of this explanation requires more than that ability is involved. It requires that S's ability has an 
appropriate level of explanatory salience. (2010: 75)

Greco notes that many factors can appear in a causal nexus that brings about an effect, and some causal factors are more important - more salient - than others in an explanation (Greco 2003; 2010: 74-5, 83-4, 104-8). Causal explanations tend to pick out one factor as primary. We say that poor lending practices led to the 2008 financial crisis, for example, even though this is just one factor within a complicated causal nexus.

Greco asks, "what factors govern the distribution of explanatory salience?" (2012: 9) He suggests this is poorly understood, and that more work is required for a full account. Greco does not offer a theory or definition of salience, but instead suggests that the salient causal factors are those factors that seem intuitively important in a causal explanation; and he describes two factors that partially determine which causal factors have salience in a causal explanation.

Firstly, causal explanations often cite what is atypical about a situation. Consider a fire in a factory. Many factors are in the causal nexus - the presence of oxygen, flammable materials, a spark - but causal explanations identify the unusual feature. Perhaps the spark is what diverges from normal, so we say the spark is the cause of the fire. The spark's abnormality renders it salient in our causal explanation. Contrast this with an environment in which sparks are normal whilst oxygen is not, such as a controlled environment within a laboratory. The causal nexus contains the same features, but we are inclined to say oxygen is the cause of the fire. This is because oxygen is the abnormal feature.

Secondly, our aims and interests can affect what causes are salient - we often identify 'the cause' as something we can control. Consider a traffic accident (Greco 2010: 74). The traffic officer may blame speeding whilst the road planner blames road design. Each person focuses on what they can control in their environment; in this manner, control can contribute to patterns of explanatory salience.

Greco contends a person's intellectual abilities have 'default salience' in explanations of true belief, owing to our reliance on one another as information-sharing beings. We are interested in tracking reliable epistemic agents, which renders salient other people's epistemic performance (Greco 2010: 73-5). In standard cases of knowledge, Greco claims competent performance enjoys default salience in an explanation of why $\mathrm{S}$ has a true belief. In a standard (non-Gettiered) case where a person perceives a sheep, the person's epistemic abilities are sufficiently salient: she arrives at a true belief because of her abilities. But this default salience can be trumped by, for example, something abnormal about the case. In cases where something trumps the causal salience of the person's abilities, the person doesn't know.

Greco claims intuitions about whether S knows co-vary with intuitions about whether the person's abilities are explanatorily salient: if the person is the 'overarching explanation', or 'salient enough', then the person knows. Greco writes,

We have no precise or systematic understanding of the rules governing explanatory salience... [but] intuitions about whether $\mathrm{S}$ knows tend to sway with intuitions about 
explanatory salience. That is, in cases where it seems that $\mathrm{S}$ knows, it seems that it is the case that S's cognitive abilities are important in an explanation why $\mathrm{S}$ believes the truth. And in cases where it seems that $S$ does not know, it seems that S's abilities are less important in such an explanation. (2010: 83-4)

Greco thereby provides a response to standard Gettier problems. In a Gettier case, some abnormal feature is rendered salient, which diverts salience away from the agent's able performance. Thus, Gettiered Roddy fails to satisfy Greco's proposed conditions. In Greco's words,

In the case of a deviant causal chain [between a person's abilities and her success], salience goes to what is deviant, and away from what is normal or usual... In Gettier cases, this default salience is trumped by something abnormal in the way that $\mathrm{S}$ gets a true belief. (2010:75)

For this reason, Gettiered Roddy does not know that there is a sheep in the field. He arrives at a true belief because of luck, and not because of his abilities.

\section{Against Greco's Covariance Claim}

But Greco's view faces problems. Greco claims intuitions about whether S knows p vary with intuitions about whether the agent's abilities are salient in a causal explanation of why $\mathrm{S}$ arrives at a true belief that $\mathrm{p}$. Call this the covariance claim. The covariance claim is key to the plausibility of Greco's view that explanatory salience captures robust virtue epistemology's 'because' relation. In what follows, I argue salience does not always go to epistemically relevant features, and so whether the agent's abilities are a salient casual feature and whether the agent knows can radically diverge. The covariance claim is false.

Let's begin with an intuitive notion of salience. Here, the explanatorily salient causal factor is that which 'stands out', or 'seems important' in a causal explanation. The cases below indicate that salience, so understood, does not co-vary with knowledge. (I subsequently introduce examples that challenge specific features of Greco's understanding of salience). Consider:

Martin and the Calculator. Average math student Martin wants to know 13x13. He enters the sum into his calculator, and thereby gains a true belief.

This is a clear instance of knowledge, but Martin's abilities are not salient. If anything the calculator is salient. Almost anyone could perform the procedure, so Martin's abilities don't 'stand out' in a causal explanation of his true belief. As a side note, this may show that Greco's notion of default salience diverges from our intuitions about salience. For Greco, Martin's abilities would be salient by default. But, this conflicts with the intuition that Martin's abilities are not salient insofar as they do not stand out or seem important.

Even if we grant Greco's (contentious) claim that Martin's competent performance enjoys default salience, default salience can be overridden by abnormal factors - this underwrites Greco's treatment of Gettier cases. So if we emend Martin's case so that calculators are a recent invention or Martin found the calculator by luck, then his default salience would be 
overridden.

If the sum is more difficult or if Martin lacks a calculator, this renders Martin's abilities more salient. But then it is less intuitive Martin knows because his evidence is weaker. Whether Martin's abilities are salient and whether he knows diverge.

Relatedly, consider Phyllis:

Physics Convention. Phyllis attends the International Physics Convention. Many wellregarded scientists attend. Misunderstanding the conventions of academic conferences, Phyllis asks a specialized physics question to the hotel's registration desk attendant. The attendant happens to know an expert on the topic is nearby, and beckons the expert. The expert tells Phyllis the answer.

In this case Phyllis's abilities are not remotely salient in an explanation of how she formed the true belief, especially compared to the abilities of the physics expert, and the well-informed receptionist. Indeed Phyllis forms a true belief despite her flawed approach. Yet Phyllis knows.

Arguably, if other scientists are present when the expert physicist talks to Phyllis we are even more inclined to attribute knowledge. This is because if the physicist's assertion were incorrect a colleague would likely intervene. But this renders Phyllis's abilities even less salient: Phyllis need not even monitor for obvious falsehood. ${ }^{6}$

Martin and Phyllis both possess knowledge even though their abilities are not salient in an explanation of why they arrived at the truth. The examples thereby resemble Lackey's simple testimony case, in which Morris learns the location of the Sears Tower, but the true belief is due to the testifier's abilities, rather than to Morris's (Lackey 2007).

Next, consider Maud.

Maud the Mathematician. Maud the mathematician is an expert in her field, who has highly honed skills in math. She has been working alone in her study for months and develops a complicated solution (S) to a mathematical problem. Finally she reaches the end of her work. 'Eureka!' she thinks. Maud hasn't yet consulted any other experts. Of course, Maud realizes she should check the results and consult her peers before she can be sure that $\mathrm{S}$ solves the problem. Nevertheless, she believes that $\mathrm{S}$ solves the problem.

In this case, Maud's abilities are clearly salient in how she formed a true belief. She was the only person developing S. Perhaps no one else could have developed S; she has highly honed math skills, substantial training, and excellent concentration. But it is less clear Maud possesses knowledge. Plausibly given the difficulty of the project, she must check the results or appeal to peer review before her belief qualifies as knowledge. Her belief might well be wrong. Certainly we are more inclined to attribute knowledge once Maud receives verification from colleagues; the more people and machines who verify $\mathrm{S}$ as a legitimate solution, the more clearly we attribute knowledge concerning her claim " $\mathrm{S}$ is a solution to the problem." But it is precisely these things that move salience away from her, and towards the scholarly community 
and her epistemic environment. As more mathematicians verify the result, Maud's role in why her belief is true stands out less: If her belief were false, someone would have noticed.

Finally, consider Fynn.

Physics Class. Fynn attends physics class. The teacher is late and Fynn desperately tries to complete his homework. He asks his classmates 'what is the nearest star to the sun?' His classmates mock him, reciting various answers, riddles, and lies. Eventually Fynn tentatively reasons towards the answer, using a combination of catching inconclusive glimpses of classmates' notes, discerning who is lying, employing a process of elimination from background knowledge, and inferring the answers to the riddles. He forms a true belief.

Like Maud, Fynn's abilities are salient in the explanation of his true belief, but our intuition that Fynn knows is weak. The epistemically friendlier Fynn's class is, the less salient his abilities are in a causal explanation of how he comes to possess a true belief, and yet the more we intuit that he knows. Again, the covariance claim faces trouble.

These four cases illustrate a rift between (i) whether S's cognitive abilities are intuitively salient in an explanation of why $\mathrm{S}$ believes the truth and (ii) whether $\mathrm{S}$ knows. They cast doubt on Greco's covariance claim, and correspondingly the idea that salience (understood intuitively) is the right way to pick out when the person knows. The cases also illustrate that, rather than co-varying with whether the agent's abilities are explanatorily salient, knowledge attributions instead depend on whether the person possesses adequate competence given the difficulty of the relevant question and the epistemic friendliness of her environment. In order to possess knowledge, a person needs a higher degree of relevant epistemic competence when the topic is challenging or when the environment is epistemically unfriendly.

So much for the intuitive notion of salience; what about the specific considerations that Greco claims govern the distribution of salience? Greco contends that salience tends to go to those causal conditions that are abnormal or can be controlled. Consider first abnormality and salience. Here, too, covariance is false. Consider Alison:

The Decryption and the Assistant. A team of secret agents attempt to crack a code. They have attempted decryption for months. Finally they consult a world expert. Attracted by a substantial consultation fee, the code-breaking genius visits the office for the day. The expert has superlative talent, and by evening the code is cracked. A trusted assistant, Alison, reads the decrypted message and thereby forms a true belief about the content.

Alison did nothing unusual and so her abilities are not salient in an explanation of her true belief. In fact, the unusualness of the expert's abilities trumps Alison's default salience. (Recall a person's default salience can be trumped by highly unusual occurrences - this is Greco's solution to the Roddy the Shepherd case.) Alison's abilities are not salient, but plausibly she knows.

The Decryption and the Infiltrator. Unbeknownst to Alison, from across the room a 
talented infiltrator reads the message over Alison's shoulder. Disguised as an electrician the infiltrator cleverly positions himself in precisely the right place at the right time to steal an unauthorized glance at the decrypted message. The infiltrator has excellent eyesight and so can read the message from a distance. And he possesses phenomenal speed-reading abilities, so he only requires a quick fugitive glance.

The infiltrator's presence in the room and epistemic abilities are abnormal features in a causal explanation of his true belief and so, according to Greco's view, the infiltrator's abilities are salient; he fulfills Greco's conditions of knowledge. According to the 'abnormal features' aspect Greco's view, the infiltrator knows, yet Alison doesn't. But there seems no relevant epistemic difference between them; they read the same document.

Now consider the second feature of salience - what can be controlled.

Math Test. Joe is taking a make-up math test. He forgets his calculator but fortunately Kim, who is also taking the make-up test, lends Joe a spare. Using the calculator and the skills he learned during the semester Joe correctly calculates the answer to a trigonometry question.

If what is salient in a causal explanation is in part determined by what one can control and one's aims and interests, then plausibly Joe's math teacher and Kim have different explanations of why Joe forms the true belief; different features in the causal nexus are salient to them. The teacher has interest in and influence over Joe's math abilities, and so his math abilities are salient to her; Kim has interest in and influence over whether Joe can access a calculator, and so this causal factor is salient to her. Both causes contribute to Joe's true belief, but which is selected as 'the cause' depends on the attributor. And so it seems that from the teacher's perspective Joe satisfies Greco's conditions on knowledge, and from Kim's perspective Joe doesn't. But the difference in the perspectives of Kim and the teacher do not seem epistemically relevant.

These cases are not intended as conclusive arguments against Greco's account. Nevertheless, I am skeptical about the prospects for Greco's account because, as we have seen, salience does not isolate epistemically relevant features. We can make changes in the salience of a person's ability without changes in whether she knows, or changes in whether the person knows without a change in the salience of her abilities. An agent's abilities can become more salient while we are less inclined to attribute knowledge, and her abilities can become less salient while we are more inclined to attribute knowledge. The covariance claim is false.

In addition to illustrating that Greco's view captures the intuitive extension poorly, these latter cases highlight a further problem for Greco's account. If what can be controlled and what is abnormal contribute to salience, this entails attributor contextualism about knowledge attributions: knowledge attributions about a particular person's belief can be true in some contexts of utterance, but not in others. Contextualism is not new to epistemology, and it is a live question whether attributor contextualism is correct. What makes Greco's attributor contextualism new and problematic is that on Greco's salience-based view it is not stakes, relevant alternatives, or anything plausibly epistemic that causes knowledge attributions to vary 
with context of attribution. Instead it is something epistemically irrelevant: the speaker's interests, what the speaker can control, and what is unusual for them.

Given these problems for Greco's view, we should seek a different interpretation of the 'because' relation invoked in robust virtue epistemology. Our criticisms of Greco's view indicate that whether a person knows doesn't co-vary with the importance of their role in forming a true belief; sometimes the person plays a small role and knows, sometimes the person plays a large role and doesn't. For this reason, attempts to address the dilemma by tweaking the requisite importance of the person's role will fail. We should jettison the idea that in cases of knowledge the person must be the main cause or sufficiently salient, and seek another way to countenance the role of epistemic abilities. The person's abilities must play some role, and a virtue-theoretic account must countenance this; but that role does not compete with other factors that contribute to forming a true belief. The size of the abilities' role is not relevant to knowledge. ${ }^{7}$

\section{Environments and Abilities}

The above cases indicate that Greco's explanatory salience interpretation of the 'because' relation of robust virtue epistemology fails: the covariance claim is false. A different account of robust virtue epistemology's 'because' relation is needed to respond to the dilemma's first horn.

But what about the dilemma's second horn? Can robust virtue epistemology explain why Barney lacks the relevant knowledge in barn façade county? The vignettes above suggest that in order to possess knowledge, the person need not be as skilled when the environment is friendly, and the person needs more skill in unfriendly environments. (Recall, for example, Phyllis and Fynn asking questions about physics in the helpful convention and the unhelpful classroom.) Greco argues - correctly in my view - that this insight can protect robust virtue epistemology from the dilemma's second horn.

The environment relativity of abilities is not specific to epistemic abilities: abilities in general are relative to environments. Sosa explains that "a disposition can be a competence only if sufficiently reliable, at least in its distinctively appropriate conditions" (2007: 106). Developing this point, Greco notes,

An ability in general is a disposition to achieve some relevant success, in relevant circumstances, relative to some environment, with a sufficient degree of reliability. We need to say 'in relevant circumstances,' because failing in some circumstances does not count against ability. For example, it does not count against Derek Jeter's ability to hit baseballs that he would fail in poor lighting conditions. We need to say 'relative to an environment', because an agent might have an ability relative to one environment but not another. For example, Jeter has the ability to hit baseballs in typical baseball environments, but presumably not in an active war zone, where he would be too distracted. (2012: 17)

When we talk about an ability a person possesses, we have in mind that the person can succeed reliably in characteristic environments. The person's failing in abnormal conditions need not 
mean they lack the ability (although it does indicate that they lack a different ability, which is required for success in the abnormal environment).

To see how this applies to barn façade county, recall that whilst Barney can normally identify barns, he lacks the ability to identify barns in the environment he is in. The ability relevant to barn-knowledge is the ability to identify barns, which requires distinguishing barns from other objects in the environment. In everyday life, if a person cannot distinguish barns from other objects - perhaps it is dark or their eyesight is poor - we would withhold knowledge attribution, even were their belief true. And, in barn façade county, if a person cannot distinguish barns from barn façades, then we withhold knowledge attribution. What is crucial for possessing the relevant ability is not that one can discriminate barns from any other thing, but that one can discriminate barns from other things in the relevant environment.

The cases above suggest that the less friendly an environment is, the more skilled a person must be in order to know. Correspondingly, in more epistemically friendly environments it is easier to gain knowledge. These points are illustrated by the physics cases. At the physics convention, the environment was excellent for Phyllis's belief-forming: she was surrounded by experts. Phyllis didn't need a high ability-level in order to know. Meanwhile, in the physics classroom, Fynn's environment made reliable belief-forming difficult. He needed a higher level of ability to determine the truth. He could obtain knowledge in this environment only if he possessed fairly advanced cognitive abilities.

Compare barn façade county to an instance of standard perceptual knowledge where a person sees a barn in a field and forms the corresponding belief 'there is a barn'. In both cases the person sees a barn and thereby forms a belief. There is no abnormal causal chain. In neither case is the person mistaken about what he saw or believing irresponsibly. The only (or at least central) things that change between the cases are the friendliness of the epistemic environment and whether the person knows. This suggests the environment plays a role in the intuitive assessment of these knowledge attributions, and thus should feature in a theory of knowledge.

Whilst it is a virtue of a theory of knowledge to match the intuitive extension of knowledge, it is even better if the theory determines the cases on the same grounds that underlie these intuitions. A theory that does this vindicates not only the intuitive extension, but also ordinary thinking and reasoning about knowledge. In entering barn façade county, nothing changed except the environment. This indicates the barn façade environment undermines Barney's knowledge. Barney lacks the high-grade competences demanded by the environment. This, I suggest, is our pre-theoretic reason behind the judgment that Barney doesn't know, and an account of knowledge should reflect these reasons.

At this juncture we can introduce some terminology. ${ }^{8}$ When evaluating 'what a person can do' there is a sense of 'ability' that is not relative to the environment the person is in at a time: a good judge of truthfulness is still a good judge of truthfulness even when surrounded by talented deceivers. She is in unfortunate circumstances, but her cognitive character has not changed; she hasn't become less skilful. In this sense 'what a person can do' is not relative to her current environment. In another sense, what a person can do is relative to environment. In an environment full of talented deceivers, she can longer do what she usually can, namely 
reliably judge characters. Whether a person possesses the relevant cognitive ability depends on her environment. Our friend does not lose an ability when she enters the room of deceivers. Her abilities are the same. But she lacks the more demanding level of ability required by her new environment.

Although Barney can distinguish barns from non-barns in normal environments, and so has barn-knowledge in normal environments, he lacks the requisite cognitive ability for barn façade county. He cannot distinguish barns from barn façades, and thus lacks knowledge in barn façade county. In other words, Barney does not satisfy the conditions of robust virtue epistemology. ${ }^{9}$

Lackey raises a concern about this kind of response to the barn façade county case. Lackey writes,

By way of response to [barn façade county cases], Greco argues that 'S's belief is the result of perception, and normally S's perception would constitute a cognitive virtue, i.e., a reliable ability or power. However, reliability is relative to an environment, and S's perception is not reliable relative to the environment in the example' (Greco, 2003: 130). While Greco may be right that reliability is relative to an environment, it is unclear why he thinks that Barney's perception is not reliable in the example under consideration. For surely Barney would form mostly true beliefs by relying on perception in the environment in question, e.g., he would form true beliefs about farmers, horses, pigs, trees, grass and so on. The only sense in which his perception is not reliable in the relevant environment is with respect to distinguishing real barns from barn façades while driving...past them. (2007: 355)

Lackey argues that Barney has the ability to detect barns because he possesses the ability to detect other objects in the area. And so the response articulated above employs a notion of ability that is too fine-grained - this way of individuating the relevant ability is ad hoc.

But now we can see a response is available. Whether the person possesses the relevant ability depends, in part, on the content believed. Barney is reliable with respect to cars and trees in his environment, because there are no façade cars or trees around. But this has no bearing on whether he is reliable with respect to barns. The presence of fake barns bears on barnknowledge. To determine reliability we must consider propositional content. This is not ad hoc or too fine-grained: whether, for example, your neighbor knows the answer to your question depends, in large part, on the content. Your neighbor might be a reliable informant with regard to baseball history, but be unreliable about French history. There is nothing ad hoc about this.

\section{Conclusion}

It is both plausible and well-motivated that Barney lacks knowledge because he lacks the epistemic abilities required by his demanding environment, namely the ability to distinguish barns from barn façades. This aspect of Greco's account provides promise for defending robust virtue epistemology against the dilemma's second horn. 
But virtue epistemology should abandon Greco's 'explanatory salience' interpretation, in favor of a different interpretation of the 'because' relation. The favored interpretation must be informed by the first horn of the dilemma - that a person can gain knowledge from simple testimony - and so the abilities' role cannot be too demanding. Interpreting the 'because' relation is the key to the success of robust virtue epistemology. ${ }^{10}$

Perhaps then, with the right understanding of the environment-relativity of abilities and the correct interpretation of the 'because' relation, robust virtue epistemology can capture the nature and value of knowledge, and argue that virtuously-formed true belief is sufficient for knowledge.

\section{Acknowledgments}

Special thanks to Heather Battaly, Jon Garthoff, John Greco, Duncan Pritchard, and Ernest Sosa for invaluable comments on earlier drafts of this essay. Thanks also to Adam Carter, Sam Carter, Jessica Brown, Abrol Fairweather, Benjamin McCraw, Peter Milne, and Sarah Wright for helpful discussion. This research was presented at the Bled 2017 epistemology conference on 'Epistemic Virtues and Epistemic Skills' and at the 2017 Joint Session.

\section{Bibliography}

Baehr, Jason (2004) 'Virtue Epistemology' Internet Encyclopedia of Philosophy. . (2008) 'Four Varieties of Character-Based Virtue Epistemology' Southern Journal of Philosophy 46:469-502.

Battaly, Heather (2008) 'Virtue Epistemology' Philosophy Compass 3(4):639-663.

Carter, J. Adam (2016) 'Robust Virtue Epistemology as Anti-Luck Epistemology: A New Solution' Pacific Philosophical Quarterly 97:140-155.

Chisholm, Roderick (1966) Theory of Knowledge Englewood Cliffs, N.J.: Prentice Hall.

Coffman, E.J. (forthcoming) 'Gettiered Belief' Explaining Knowledge: New Essays on the Gettier Problem Rodrigo Borges, Claudio de Almeida, and Peter D. Klein (eds.) Oxford University Press.

DePaul, Michael and Linda Zagzebski (eds.) (2003) Intellectual Virtue: Perspectives from Ethics and Epistemology Oxford University Press.

Fairweather, Abrol and Carlos Montemayor (2017) Knowledge, Dexterity, and Attention: A Theory of Epistemic Agency Cambridge University Press.

Fumerton, Richard (2011) Review of Achieving Knowledge by John Greco Notre Dame Philosophical Review.

Gardiner, Georgi (2011) A Defence of Robust Virtue Epistemology, Master's Thesis, University of Edinburgh. - (2017) 'Safety's Swamp: Against the Value of Modal Stability' American Philosophical Quarterly 54(2):119-129.

Gendler, Tamar and John Hawthorne (2005) 'The Real Guide to Fake Barns: A Catalogue of Gifts For Your Epistemic Enemies’ Philosophical Studies 124:331-352.

Gettier, Edmund (1963) 'Is Justified True Belief Knowledge?' Analysis, 23:121-3.

Goldberg, Sandy (2011) 'The Division of Epistemic Labor' Episteme 8(1):112-125. 
Goldman, Alvin (1976) 'Discrimination and Perceptual Knowledge' Journal of Philosophy 73:771-91.

Greco, John (2003) 'Knowledge as Credit for True Belief' in DePaul and Zagzebski (2003:111-34). - (2010) Achieving Knowledge Cambridge University Press. . (2012) 'A (Different) Virtue Epistemology' Philosophy and Phenomenological Research 85(1):1-26. . (forthcoming) The Transmission of Knowledge Cambridge University Press.

Lackey, Jennifer (2007) 'Why We Don’t Deserve Credit For Everything We Know' Synthese 158:345-61. . (2009) 'Knowledge and Credit' Philosophical Studies 142:27-42.

Littlejohn, Clayton (2014) 'Fake Barns and False Dilemmas' Episteme 11(4):369-389. Lord, Errol (forthcoming) 'Epistemic Reasons, Evidence, and Defeaters' The Oxford Handbook of Reasons and Normativity Daniel Star (ed.) Oxford University Press.

Mackie, J. L. (1965) 'Causes and Conditions' American Philosophical Quarterly 2:245-64. - (1974) The Cement of the Universe: A Study of Causation Oxford: Clarendon Press.

Miller, Alan (2016) 'Abilities, Competences, and Fallibility' Performance Epistemology Miguel Ángel Fernández Vargas (ed.) Oxford University Press.

Nimtz, Christian (forthcoming) 'Knowledge, Abilities, and "because"-Clauses. A Critical Appraisal of Virtue-Theoretic Analyses of Knowledge' Knowledge, Virtue and Action Tim Henning and David Schweikard (eds.) Routledge.

Pritchard, Duncan (2005) Epistemic Luck Oxford University Press. . (2007) 'Recent Work on Epistemic Value' American Philosophical Quarterly 44:85110. . (2010) Chapters 1-4 in Haddock, A. Millar, A., and Pritchard, D. H. The Nature and V alue of Knowledge: Three Investigations Oxford University Press.

. (2012) 'Anti-Luck Virtue Epistemology' Journal of Philosophy (109):247-79.

Riggs, Wayne (2002) 'Reliability and the Value of Knowledge' Philosophy and Phenomenological Research, 64:79-96.

. (2007) 'Why Epistemologists are so Down on Their Luck' Synthese 158:329-344. . (2009) 'Understanding, Knowledge, and the Meno Requirement Right' in Haddock, Millar, and Pritchard (eds.) Epistemic V alue Oxford University Press pp. 331-8. Sosa, Ernest (1988) 'Beyond Scepticism, to the Best of our Knowledge' Mind 97(386):153188.

Press. . (1991) Knowledge in Perspective: Selected Essays in Epistemology Cambridge University . (2003) 'The Place of Truth in Epistemology' in DePaul and Zagzebski (2003:155-179).

Press. . (2007) A Virtue Epistemology: Apt Belief and Reflective Knowledge I Oxford: Clarendon . (2017) Epistemology Princeton University Press.

Turri, John (2011) 'Manifest Failure: The Gettier Problem Solved' Philosopher's Imprint 11(8):1-11.

Turri, John, Mark Alfano, and John Greco (2017) 'Virtue Epistemology' The Stanford Encyclopedia of Philosophy, Edward N. Zalta (ed.).

Zagzebski, Linda (1996) Virtues of the Mind Cambridge University Press. 
1 One might maintain epistemic virtue is central to the nature and value of knowledge even if epistemic virtue is neither necessary nor sufficient for knowledge. One might hold, for example, that 'virtuously-held true belief characterizes typical instances of knowledge, even if marginal instances do not conform to the definition.

2 One must distinguish between explaining why the belief is true (rather than false) and explaining why the belief is held (rather than not believed). The former is the relevant relata. See Zagzebski (1996: 297); Sosa (2007: 96-7).

3 Gardiner (2011) argues Pritchard fails to motivate his bipartite structure of knowledge.

4 See Pritchard (2007) and Riggs (2009). Greco (2003; 2012) and Sosa (2007; 2017) understand the value of knowledge through the broader phenomenon of performance normativity. Gardiner (2017) argues that accounts of knowledge that posit an explicit anti-luck condition cannot explain the distinctive value of knowledge.

$5 \quad$ The dilemma is pressed by Lackey $(2007 ; 2009)$ and Pritchard (2012), and was originally an objection to the 'credit thesis.' The credit thesis - defended most explicitly by Riggs (2002), but also in various guises by Greco (2003), Sosa (2003), and Zagzebski (2003) - posits the difference between knowledge and mere true belief consists in a person deserving credit for the truth of her belief.

6 Goldberg (2011) discusses the epistemic role of third parties in testimonial exchange.

7 Greco (2012; forthcoming) acknowledges the person's role should not be understood in a 'quantitative' way, such as requiring a certain amount of importance, and instead interprets salience qualitatively. But Greco retains the central idea that in cases of knowledge the person's abilities must play a salient role in explaining the true belief.

$8 \quad$ See also Sosa's (2017) 'SSS' structure of competences and Littlejohn (2014).

9 This kind of response to the dilemma's second horn is found in Greco (2003; 2010; 2012), Littlejohn (2014), Miller (2016), and Gardiner (2011), amongst other places. For objections, see Fumerton (2011) and Gendler and Hawthorne (2005). I think these objections are surmountable, but I do not have space to explore them here.

10 For discussion of the 'because' in robust virtue epistemology, see Sosa (2017), Turri (2011), Carter (2016), Gardiner (2011), Fairweather and Montemayor (2017), Nimtz (forthcoming), and Littlejohn (2014). In Gardiner (2011) I claim that interpreting the 'because' relation of robust virtue epistemology using Mackie's $(1965 ; 1974)$ 'inus-conditions' account of causation can resolve the dilemma. I argue that in all and only cases of knowledge the person's cognitive abilities are (at least) an inus-condition for the cognitive success. Sosa (2017) interprets the 'because' as a manifestation relation: S knows p only when the cognitive success manifests cognitive competence. 